\title{
Análisis práctico de la obra de Pere Portabella (1967-1976): la subversión de la Manera de Representación Institucional a través de la música
}

\author{
Josep Torelló Oliver \\ Centre de la Imatge i la Tecnologia Multimèdia (CITM) \\ Universitat Politècnica de Catalunya (UPC), España \\ Jaume Duran Castells \\ Universitat de Barcelona (UB), España
}

\begin{abstract}
This article analyzes part of the filmography of the Catalan director Pere Portabella (Figueres, 1927) in the period 1967-1976. The analysis focuses on those sequences in which Portabella articulates a music-image relationship that allows him to subvert the traditional Institutional Mode of Representation (Burch 2008), while developing a cinematic proposal that is typical of film modernity, also called Modern Mode of Representation. We consider that this subversion of the institutional language happens when it is articulated a music and an image that tense the classical definition of institutional diegetic space-time. We analyze 8 paradigmatic cases that permit us to understand how the aesthetic relationship between music and image in their work allows to develop a modern cinematography proposal.
\end{abstract}

Keywords: Pere Portabella, Music's Theory, Modernity Filmography, Avant-garde

\section{La modernidad cinematográfica}

A finales de los años cincuenta se desarrolla una práctica cinematográfica que se conoce como cine de la modernidad (Font 2002; Quintana 1996). Es en este periodo cuando los cineastas europeos - se cita $T e$ querré siempre (Viaggio in Italia, Roberto Rossellini, 1954) como el filme inaugural- comienzan a articular una nueva manera de expresarse a través del cine, la cual se caracteriza por poner en cuestión la tradición fílmica desarrollada en la primera mitad del siglo XX, aquella que Burch denomina el Modo de Representación Institucional (MRI) (Burch 2008). A diferencia del cine primitivo, el lenguaje institucional se basa en la convención de una representación moderna y cinematográfica de las dimensiones espacio-tiempo. El concepto del MRI propuesto por Burch tiene una correspondencia teórica en el concepto Hollywood clásico, expuesto por Bordwell y su equipo (Bordwell et al. 1997), quienes definen que la articulación estética de esta institución funciona como un conjunto de normas, recursos formales y sistemas —un sistema de lógica narrativa, uno de representación temporal y uno de representación espacial- que se relacionan entre ellos para crear la diégesis fílmica (Bordwell et al. 1997, 7). La teoría cinematográfica entiende que los cineastas europeos empiezan a articular entonces un cine que, en esencia, trata de subvertir estos fundamentos del MRI.

\section{Pere Portabella (1967-1976), cineasta vanguardista}

Es en esta renovación del cine europeo moderno donde podemos contextualizar la obra del director catalán Pere Portabella (Figueres, 1927). La alineación de la actividad artística de Portabella con estos supuestos de ruptura y subversión del lenguaje cinematográfico - la reacción contra la institución-es clara y no se puede separar de la condición política del autor: una activa oposición al régimen franquista desde la clandestinidad, la cual condiciona la posición estética del conjunto de su obra.

Portabella, en el periodo 1967-1976, realiza una obra personal que le sitúa claramente en este panorama diacrónico de evolución del lenguaje que propone el término cine de la modernidad. En referencia a la estética de su filmografía, la no-narratividad se manifiesta ya en los primeros filmes, No compteu amb els dits (1967) y Nocturn 29 (1969), desarrollados en estrecha colaboración con el poeta Joan Brossa. Y en toda su carrera posterior Portabella formula una cinematografía que pone especial énfasis en subvertir el espacio-tiempo diegético institucional. Esta forma de articular el filme es genuina de la modernidad y la ensaya en Miró, l'altre (1969), Play Back (1970), y en los importantes largometrajes Vampir-Cuadecuc (1970) y Umbracle (1972), donde «la política irrumpe como no lo había hecho hasta el momento en el cine de Portabella» (Fanés, 2008: 36)1. Este vital periodo de creación cinematográfica de Pere Portabella en la clandestinidad política (1967-1976) termina con el cortometraje experimental Acció Santos (1973) y con el importante filme Informe general sobre algunas cuestiones de interés para una proyección pública (1976), un documento de casi tres horas de duración que radiografía las diferentes fuerzas políticas y sociales de la España del momento. Esta actividad se interrumpe el año 1978, cuando Portabella puede abandonar la política clandestina para incorporarse a la política institucional, estando una década sin producción cinematográfica alguna. Las siguientes obras del director pertenecen a otro conjunto el cual consideramos que debe analizarse por separado. Otra razón, no menos importante, es que la modernidad cinematográfica evoluciona rápidamente a partir de medianos de los años ochenta, y lo hace hacia un escenario de difícil definición que podemos considerar como «posmoderno» - marcado por la evaporación de las categorías, la hibridación estilística y los cambios tecnológicos (Font 2012, 24)—. Un espacio, aún, discutido y discutible. Para analizar los filmes 
de Portabella a partir de Pont de Varsovia (1989) en adelante, deberíamos situarnos en otro marco teórico y referencial del que utilizamos para estudiar la Manera de Representación Moderna (MRM) (Duran 2013).

Así, la producción cinematográfica de Pere Portabella llegará hasta el cine digital, produciendo Die Stille vor Bach (2007). Este film, «nacido con la intención de ilustrar las Variaciones Goldberg de Johann Sebastian Bach» (Fanés 2008, 40), es un film que combina, de manera particular, el cine no narrativo, con apuntes históricos y musicales. En el filme, la música tiene un papel predominante en la articulación de la dramaturgia. Finalmente, en 2015, Portabella estrena su, hasta el momento, último filme: Informe General II, el nuevo rapto de Europa en el que hace una revisión, desde un punto de vista actual, del filme de 1976.

En todo caso, la articulación del espacio-tiempo diegético en los filmes del periodo estudiado (19671976) - que por razones temporales, políticas y estéticas, entendemos unitario y representativo- es sorprendente, y consideramos que la música es uno de los elementos importantes - aunque no el únicocon el que Portabella trata de subvertir la Manera de Representación Institucional.

\section{Estado de la cuestión de la música en el cine}

La hipótesis de nuestro estudio es que la manera con que Portabella articula la música en sus filmes es una de las características que nos permite catalogar su cine como una superación del Modo de Representación Institucional. Para corroborarlo debemos poner el foco en diversos aspectos: por un lado, estudiar el marco teórico que trata la cuestión de la relación estética imagen-música; por otro, analizar parte de la filmografía del director Pere Portabella en el periodo 1967-1976.

Cabe subrayar que el análisis de la relación música-imagen plantea una serie de inconvenientes inherentes a su marco teórico y metodológico. El principal problema es que, aunque se avanza positivamente en la construcción de un marco teórico sólido (Fraile, 2016), partimos de un estado de la cuestión de la disciplina de análisis de la música y de los filmes que se define por ser un panorama no estructurado (Infante del Rosal y Lombardo, 1997: 206), hecho de contribuciones teóricas dispersas e irregulares. Además, la teoría y la práctica de la imagen cinematográfica parece que se haya resistido a llevar a cabo un análisis interdisciplinario de sus elementos «es un tema que no parecía tener mucho interés con anterioridad; [...] quizá porque el campo de la imagen por sí sola arrastraba ya demasiado apego desde sus comienzos, originando un sinfín de estilos y corrientes» (Jaume Duran en Torelló 2015, 9). Aunque es evidente que la música -0 cualquier otro elemento externo a aquello propiamente iconográfico- es un elemento relevante en la codificación del lenguaje audiovisual, aunque, tradicionalmente, su estudio en este tipo de análisis audiovisuales ha sido prácticamente nulo. En este sentido, recordemos la cita del teórico Béla Balázs: «La música pertenece al mecanismo de la imagen del film, como la luz y la sombra» (Balázs 1978, 233).

\section{Una definición del estatus de la música en relación a la imagen}

En la lectura de la teoría que estudia la relación música-imagen aparece la dificultad de sintetizar, desde un punto de vista conceptual, este conjunto bibliográfico y relacionarlo con la teoría cinematográfica general. Parece que no hay un conjunto teórico consensuado que responda a la cuestión ¿qué define el estatus de la música en el cine? Aunque hay destacables aproximaciones, como Historia y Teoría de la música en el cine (Presencias afectivas) (1997), de Carlos Colón, Fernando Infante del Rosal y Manuel Lombardo; o el conjunto de la obra ensayística que realiza Teresa Fraile, quien sistematiza la cuestión tratada en artículos como «Músicas posibles: tendencias teóricas de la relación música-imagen» (Fraile 2005), en su tesis doctoral La creación musical en el cine español contemporáneo (Fraile 2008) o, recientemente, en «Música de cine en España: crecimiento y consolidación de una disciplina» (Fraile 2016).

Desde nuestro punto de vista, hemos planteado una propuesta de categorización original que estudia la relación sincrónica entre la música y la imagen. $Y$ a partir de la teoría que se ha escrito en torno a la cuestión, de las categorías que se describen y de las metodologías que se establecen a partir de los trabajos compilatorios y analíticos mencionados, hemos definido el estatus de la música en el audiovisual, en la medida de lo posible, en un solo sistema analítico y teórico.

La propuesta original que planteamos a continuación es la que, a la vez, nos sirve para analizar diversas secuencias de la filmografía del autor, comprendiendo el estatus de la música en el audiovisual como un conjunto de funciones y dominancias, un sistema en que una música puede tener varios estatus a la vez.

Entendemos que el estatus de la música en el cine se articula a partir de tres factores:

1) Estatus estructural-ontológico: define en el papel de la música en la articulación del «tercer elemento» (Fraile 2008, 51) que es el audiovisual; es decir, estudia las contribuciones que la música tiene en la construcción del flujo icónico-sonoro de representación cinematográfica. Es un estatus que tiene relación con la capacidad de la música de apoderarse la imagen y de definir su trama epistemológica.

2) Estatus narrativo-funcional: estudia la presencia de la música en la articulación de la dramaturgia del film; es decir, estudia como la música se relaciona con todas aquellas cuestiones que permiten que el lenguaje audiovisual desarrolle sus capacidades narrativas, subrayar significados que, desde la vertiente dramática, son claves en la construcción del discurso. Es un estatus que tiene relación con de qué manera la música es capaz de articular una definición geográfica, histórica, cultural, sociológica, sentimental y etcétera del relato iconográfico expuesto.

3) Estatus poético-autónomo: estudia como la música se concreta sólo en su condición de elemento subjetivo e inmediato en relación a la recepción del film, y no como elemento significante en relación a 
la imagen representada en pantalla. Es un estatus que tiene relación con las propias características del campo epistemológico musical; es decir, estudia la capacidad de la música presente en el film -el elemento más flexible de la articulación audiovisual (Chion 1997, 218)—, de articular la significación de las propias capacidades autónomas del elemento música en el seno del flujo cinematográfico. Se estudia la manifestación musical de manera autónoma en la relación música-film-espectador, obviando, por momentos, que ésta está vinculada a una imagen.

\section{La subversión de los códigos de la MRI: análisis del estatus de la música en los filmes del periodo 1967-1976}

\section{Caso 1: No compteu amb els dits (1967)}

En general, en el primer mediometraje dirigido por Pere Portabella, No compteu amb els dits (1967), observamos el embrión de algunas pautas o planteamientos genéricos referidos a la articulación la música en su propuesta artística, que Portabella repite de manera constante en el conjunto de la filmografía analizada. Cabe destacar que el compositor de la música original es, en este primer caso, Josep Maria Mestres Quadreny, lo cual marca el carácter general del film en los aspectos estético-musicales —música dodecafónica y experimental-.

Hay una escena que se articula a partir de una voz de la cual no vemos su fuente sonora, una situación que Chion define como la «escucha acusmática» (Chion 1993, 74). Escuchamos unos ejercicios de voz similares a aquellos que los cantantes suelen hacer en la previa de una audición o de una grabación a modo de calentamiento vocal; ejercicios que sirven para preparar las cuerdas vocales para el canto, para calentar la voz. Es interesante que se utilice un elemento que no es propiamente musical, es decir, no es una acción musical sino su preparación previa. Es evidente que nos podemos preguntar, ¿estas escalas de notas son propiamente música? Esta capacidad de Portabella de situarse en el límite de la definición o indefinición del estatus musical o semi-musical, en la relación del sonido con la imagen, es una de sus concepciones cinematográficas recurrentes.

La banda sonora que escuchamos en esta secuencia tiene un estatus epistemológico poco preciso: es alguien articulando alguna forma de canto o el sonido gutural de un ejercicio físico. En todo caso, lo que hace interesante el análisis es no percibir con claridad si consideramos que lo que escuchamos es sonido no musical o bien es música. En este sentido subrayamos la coincidencia de este enfoque audiovisual con el planteamiento teórico que expresa Chion en $L a$ Audiovisión (1993): la arbitrariedad manifiesta —sólo fundamentada en una distinción cultural- entre lo que se considera sonido -y en última instancia, ruidoy lo que se considera música (Chion 1993, 190). De alguna manera, Portabella explora el límite entre lo que consideramos música y lo que consideramos sonido, y como, en relación a esta duda o indefinición, se crea una diégesis particular, experimental y no muy proclive a considerarse una representación institucional. De hecho, la música-sonido presente en esta muestra tiene un estatus estructural-ontológico ya que este canto que escuchamos articula la única dimensión sonora de la imagen en la secuencia.

\section{Caso 2: Nocturn 29 (1969)}

El segundo largometraje de Portabella, Nocturn 29 (1969), es una muestra de como es de importante, en los primeros filmes del director, la presencia de la música dodecafónica. Cabe subrayar que, usando este tipo de música, se rompe una de las cuestiones que la bibliografía remarca como una constante en la presencia de la música en el audiovisual, aquella que Fraile $(2005,297)$ teoriza como el «sinfonismo clásico», rasgo propio del MRI: el hecho de adoptar, para una expresión artística contemporánea, una tipología de música que reproduce características clásicas. Esta secuencia es un ejemplo del uso de la música contemporánea en la "expresión cinematográfica» ${ }^{2}$ del «cine de la modernidad»: un planteamiento de contrapunto dramático entre la música y la imagen -tal como, sin mucho éxito hasta el advenimiento de la modernidad audiovisual, había teorizado Adorno (2007)_. Solamente por este motivo —el uso de una música estéticamente contemporánea-, nos encontramos ya ante una articulación transgresora o contraria a las tendencias expresadas por el MRI, de la cual diferentes secuencias de los filmes No compteu amb els dits (1967), Nocturn 29 (1969) y Umbracle (1972), son buenos ejemplos. Con todo, cabe decir que la modernidad cinematográfica, según la perspectiva del teórico Michel Chion, se ve menos afectada por el estilo musical que por la manera en como esta se integra en el filme (Chion 1997, 153); es más una cuestión de uso que de estética musical.

Con respecto al estatus de la música en la secuencia, éste no es fácil de concretar. El sonido de unas notas dispersas de piano sirve a Portabella para encadenar dos localizaciones diferentes: la actriz Lucía Bosé paseando por el Laberinto de Horta en Barcelona, y una secuencia en casa de la misma protagonista. En este sentido, entendemos que la música participa de un estatus ontológico, ya que no hay ningún otro elemento sonoro que defina la diégesis. Como enlace de las dos secuencias, visualizamos una melodía desestructurada, experimental, sin armonía aparente. ¿Qué estatus posee la música de esta secuencia? En un sentido, asistimos a la transgresión de la dramaturgia cinematográfica expresada en el MRI a través de la música contemporánea. La música es articulada en un estatus narrativo-funcional, ya que interpela la narratividad del filme $y$, de hecho, trata de desmenuzarla.

\section{Caso 3: Miró, l'altre (1969)}

La intencionalidad con la que Portabella articula la música con relación a la imagen y a la narratividad del montaje se repite, quizás de forma más elaborada, en 
este fragmento analizado. El cortometraje Miró, l'altre (1969) es un hito importante en la obra del director. Por un lado, el filme representa la primera colaboración de Carles Santos como compositor de una música original - hecho que le da a la propuesta cinematográfica una fuerte personalidad-; por otro, el planteamiento fílmico: «[...] abandona la lógica del lenguaje cinematográfico para someterse a otro tipo de orden, casi inconsciente, que nos recuerda al de la música. Como si fueran notas, las imágenes se repiten en una forma de bucle una vez tras otra» (Fanés 2010, 483).

En lo que hace referencia a la articulación de la imagen, el cortometraje está compuesto por diversos fragmentos: la presentación de Miró antes de la performance que le lleva a pintar el vitral exterior del Colegio de Arquitectos de Cataluña, las imágenes en color del artista pintando el mural, el pintor después de realizar la obra, trabajadores del Colegio limpiando el vitral y arrancando la obra de Miró con espátulas, etcétera.

En lo referido al sonido y la música, encontramos, también, diferentes pasajes. La banda de sonido está formada por tres elementos diferenciados: un par de voces que cantan a cappela escalas que, de manera progresiva, van subiendo el tono; unos objetos sonoros no identificados; $y$, finalmente, un piano que toca una melodía no muy definida. Como si fuesen transiciones sonoras entre cada fragmento de la banda de sonido, encontramos espacios del filme que se articulan a $0 \mathrm{~dB}$. En el conjunto de la obra, no hay sonido ambiente ni sincronía sonora con la imagen que siga lógica alguna.

El primer fragmento -el blanco y negro en que Miró se está preparando para pintar-y el segundo - la acción performativa de pintar el vitral- están, por un lado, desunidos y contrapuestos por el montaje que los diferencia como partes, y también por la transformación que sufre la imagen, que pasa del blanco y negro inicial al color, hecho que ayuda a esta fragmentación. Solamente el audio que escuchamos les da continuidad y unidad. $Y$ aunque la presencia de una voz no visualizada en pantalla es un recurso que Portabella ensaya en filmes anteriores - por ejemplo, en la secuencia comentada de No compteu amb els dits-, esta propuesta es más radical y trabajada: se articula una secuencia que busca el límite de la distinción música-sonido-ruido a la vez que la unidad de la "expresión cinematográfica» se sustenta casi exclusivamente en los elementos sonoros.

Desde nuestro punto de vista, definimos su presencia en el filme bajo la dominancia del estatus estructural-ontológico, ya que aquí tampoco existe ningún otro elemento en la banda de sonido: es la música la que permite estructurar el campo epistemológico del cortometraje. Por otro lado, consideramos que la música de este cortometraje tiene también un estatus narrativo-funcional; o, en todo caso, lo tiene en un sentido de oposición al MRI: la música del fragmento pretende estructurar una propuesta antinarrativa. Para tal afirmación nos sustentamos en que en todos los fragmentos del cortometraje aparece una música cíclica, de bucle; una música que parece que avanza en lo temporal —va subiendo de tono- pero que, en realidad, al no tener una resolución ni progresión armónica, siempre sitúa al espectador en un mismo tiempo de la acción. Es cierto que en los fragmentos centrales del filme -en los que se pinta o se borra el mural-, la música aporta una idea de temporalidad, en parte propia del MRI; pero en los fragmentos de inicio y final del cortometraje, aquellos en que el bucle se realiza también a nivel icónico, se rompe esta narratividad y la idea de progresión temporal del audiovisual se difumina, presentando una forma cinematográfica que transgrede claramente la propuesta institucional o clásica. En este caso, la subversión del espacio-tiempo diegético es aún más honda que en los casos anteriores.

\section{Caso 4: Play Back (1970)}

El cortometraje Play Back (1970) permite a Portabella dar continuidad al tándem creativo iniciado con Santos. Esta colaboración tiene, en este momento, el ideario del arte conceptual como telón de fondo. Play Back es un cortometraje en el que se lleva al límite la relación estética entre la música y el sonido; se busca a menudo la frontera que les separa de una manera radical y vehemente.

En este sentido, el filme nos muestra un ensayo del Coro del Gran Teatro del Liceo de Barcelona en el que las coristas cantan las notas de una partitura para orquesta, con la particularidad que en la ejecución no se hace ninguna entonación, pero se verbaliza rítmicamente cada nota. Es decir, se reparten las partituras de los diferentes instrumentos orquestales a la coral, y esta simula interpretar la partitura, pero sin entonar, solamente verbalizando en voz alta, y a ritmo, la nota que hay escrita en el pentagrama. El resultado es un experimento cinematográfico-musical particular: una reflexión sobre el objeto música que se repetirá en otra secuencia del filme Umbracle (1972) y en el cortometraje Acció Santos (1973).

Fanés argumenta que «en el filme contemplamos al compositor dirigiendo una parte del Coro, que canta fragmentos de Tanhauser, Lohengrin y de $\mathrm{La}$ Valquiria, aunque la música parece corresponder más a una composición de corte minimalista del mismo Santos que no a una partitura de Richard Wagner. El malentendido se debe al hecho de que el coro lee las notas con el ritmo adecuado, pero prescindiendo de la entonación» (Fanés 2010, 485).

El filme se articula con sonido directo y escuchamos y visualizamos como Santos habla y dirige el ensayo. Por lo tanto, desde nuestra perspectiva, la música concreta que escuchamos no tiene un carácter dominante en el estatus estructural-ontológico. Sí que lo tiene, sin embargo, en el aspecto narrativo - $u$, otra vez, quizá, mejor dicho, en la transgresión de lo narrativo-; es decir, la música, como tantas otras veces en la filmografía de Portabella, condiciona parte del carácter antinarrativo del cortometraje. A diferencia del caso anterior, la propuesta audiovisual no es cíclica, ni en la articulación de la imagen, ni en su música; por lo tanto, en este sentido, el espacio-tiempo de la diégesis puede ser homologable a una propuesta institucional. 
Lo transgresor de esta secuencia es la conjunción de «[...] un martilleo de sonidos trepidantes, reforzados por los movimientos nerviosos y casi espasmódicos de la cámara» (Fanés 2010, 485). Lo que es subversivo es la particular presentación de la forma música que, creando una tensión latente en el artefacto expresivo, nos permite reflexionar sobre la naturaleza de lo musical como fenomenología dentro del audiovisual. A nivel visual, además, no hay escotomización de la cámara de grabación, tendencia —el derrumbe de la cuarta pared-que es otra de las características de la Manera de Representación Moderna (MRM).

\section{Caso 5: Vampir-Cuadecuc (1970)}

El siguiente largometraje, Vampir-Cuadecuc (1970), se sitúa plenamente dentro de la etapa conceptual del director. El film tiene un buen número de secuencias que comparten características similares. Durante su transcurso, encontramos varios momentos en que se articula la banda sonora a $0 \mathrm{~dB}$. De esta manera consideramos que se establece una dialéctica entre la imagen y el sonido en la que el campo epistemológico de la «expresión cinematográfica» queda intencionadamente desequilibrado o, incluso, mutilado; una dialéctica descompensada que se basa en sacarle a la "expresión cinematográfica» su dimensión sonora, y dejar sólo la dimensión icónica -propio de una expresión del Modo de Representación Primitiva (MRP)—. La búsqueda de esta descompensación le da a la secuencia una expresividad muy dura, que incómoda, y que, de manera evidente, nos recuerda lo que relata Maksim Gorki cuando experimenta, por primera vez, la visualización de una imagen en movimiento que no está acompañada por ninguna dimensión sonora: el Reino - añade que fantasmagórico- de las Sombras (Burch 2008, 41).

En otros momentos del filme, aunque la banda sonora no se articule a $0 \mathrm{~dB}$, esta se forma únicamente con una nota que modula su tonalidad, que tiene cierta melodía, y que es cíclica. Escuchamos unas vibraciones que tienen un importante matiz de reverberación, trabajado probablemente en la postproducción del sonido en el estudio. Así, la dialéctica imagen-sonido no está del todo descompensada — hay sonidopero sí que ésta es muy extrema. Consideramos que la presencia de esta música minimalista subvierte el canon narrativo. Al presentarse una idea musical cíclica y poco armónica, la conjunción que ésta consigue con la imagen es del todo particular. Se articula el "expresión cinematográfica» a nivel estructural, se hace avanzar, en cierta medida, la dramaturgia de la secuencia, pero ésta se convierte en una articulación tan extrema que le sigue dando un carácter extraño a la imagen; un espacio-tiempo diegético, en algún aspecto, que es mutilado.

Desde una perspectiva benjaminiana entendemos que el sonido y la música reconstruyen el «aura» (Benjamin 2012, 13): desde una perspectiva ontológica, de la imagen -la apodera a un nuevo status-; la música que articula Portabella en muchas de las secuencias del filme hace que se sitúe en el límite del "expresión cinematográfica» resultante; se produce una cierta ambivalencia en la construcción del campo epistemológico —una indefinición buscadaentre «lo real» y «lo fantasmagórico».

\section{Caso 6: Umbracle (1972)}

La articulación de la música en el filme Umbracle (1972) es variada, y es en este filme donde se consolidan un conjunto de prácticas iniciadas en otros filmes. La secuencia que analizamos también procura subvertir la estructuración del espacio-tiempo diegético institucional a través del bucle y la repetición musical.

El patrón dramático de la secuencia es el siguiente: se presenta una acción - la actriz llega a su casa, pone música en el tocadiscos y se dispone a llamar por teléfono-. Hasta este momento la música tiene un estatus estructural-ontológico en el conjunto de la secuencia, a la vez que una vertiente narrativa; la acción fluye hacia adelante en un sentido temporal. Pero de repente, de manera manifiesta, se rompen ambos aspectos - la ontología y la dramaturgia de la muestra-, ya que la música que escuchamos entra en bucle - hay un cambio en su estatus - sin que haya ninguna causa diegética o dramatúrgica que justifique dicha alteración.

A diferencia de otras secuencias analizadas en las que solamente es la banda sonora la que se repite rítmicamente-, en esta la imagen también entra en el loop repetitivo y acompaña a la música para situarse conjuntamente en este no-tiempo y noespacio diegético articulado en el filme. El director rompe el continuum de la "expresión cinematográfica» y cuestiona el tiempo narrativo de la secuencia a través de ambas dimensiones del audiovisual: lo icónico y lo sonoro.

Fanés lo explica de manera clara: «A menudo la banda de sonido se queda parada en un acorde o un ruido, tal como observamos también en Miró, l'altre. [...] Venga del minimalismo americano o venga de Bach, el compositor recurre en Umbracle a una serie de técnicas basadas en la repetición de células sonoras. [...] en una de las últimas escenas del filme, imagen y sonido se superponen en un enloquecido frenesí repetitivo. Es el momento en el cual el personaje de la mujer llega a casa y pone un disco, el tercer movimiento de la sinfonía Pastoral de Beethoven. Después se sienta y empieza a telefonear: en este punto, la música se encalla y Santos convierte el núcleo sonoro beethoveniano en una repetición sin fin - a la manera de un disco rayado- a la vez que los diversos planos - hasta siete-, que dividen el gesto de la mujer de coger el teléfono, marcar el número, acercarse el auricular a la oreja, se repiten cada uno un número indeterminado de veces, siguiendo la pauta del ritmo entrecortado de la música» (Fanés 2008, 67-68).

Es decir, el fragmento recurre a la repetición de células sonoras y visuales para destruir la articulación clásica del audiovisual a través de la repetición y la subversión del espacio-tiempo diegético cinematográfico. 


\section{Caso 7: Acció Santos (1973)}

En 1973 Portabella realiza el cortometraje de Acció Santos que es una de las últimas expresiones de la etapa conceptual del autor - tendencia que nunca se cierra del todo a lo largo de su carrera-. El film se puede entender como una reflexión en torno al estatus de la música en el audiovisual; una reflexión sobre la música en sí misma —su naturaleza-, y sobre el papel y la epistemología de ésta en el contexto contemporáneo del autor. Así pues, el trasfondo del film, tal como hemos visto, no es conceptualmente nuevo - cuestionar el objeto música-, lo que sí es relevante es que, en este caso, todo el cortometraje se estructura en torno a esta idea.

El cortometraje plantea un primer estatus diegético y escénico de la música: Santos interpreta al piano de cola un preludio de Fédéric Chopin que es, a la vez, registrada audiovisualmente. En este punto, la música articula formando parte de los tres estatus mencionados: encontramos una presencia estructural de la música ya que ésta da forma a la sincronía que se establece con la imagen en el campo epistemológico; la música tiene una dimensión narrativa porque acompaña la causa-efecto de lo que observamos y escuchamos en pantalla; y, finalmente, la música tiene un estatus poético, ya que se escucha la interpretación entera de una pieza musical, por lo que es perfectamente posible captar la música de manera autónoma en su relación con la imagen. Ahora bien, la segunda parte del cortometraje modula todo lo representado hasta el momento. Vemos a Santos sentado en una mesa; con la ayuda de un magnetófono escucha la grabación de la pieza que acaba de interpretar y nosotros, a la vez, sentimos la música que suena por el magnetófono. La presencia de la música ahora es grabada - no interpretada en directo-, pero sigue siendo una música que pertenece a la diégesis del film, aunque su fenomenología musical haya cambiado.

Finalmente, cuando Santos se pone los auriculares, el "expresión cinematográfica» se queda a $0 \mathrm{~dB}$; sentimos la ausencia de la música, la que suena por el magnetófono, pero sólo Santos la puede escuchar. Esta es una ausencia narrativa: vemos que Santos escucha música con unos auriculares y entendemos la relación causa-efecto de la no sonorización. Pero a nivel ontológico, otra vez, esta ausencia tensa la dialéctica imagen-sonido, mostrando como la articulación de la música condiciona el campo epistemológico de la MRI, y como Portabella, desde una propuesta propia de la modernidad, la supera, articulando - por presencia y ausencia — tal como propone Chion, una música de carácter clásico a la manera cinematográfica moderna.

\section{Caso 8: Informe general (1976)}

En la primera secuencia del último de los filmes analizados del periodo, Informe general sobre algunas Cuestiones de interés para una proyección pública (1976), Portabella vuelve a articular una presencia de la música en la manera en que ha sido utilizada en otros filmes anteriores. Un lento fade in de instrumentos de cuerdas o de vientos, sonidos de fricción — también utilizados en Vampir-Cuadecuc (1970) y Umbracle (1972) - que aparecen in crescendo y connotan una imagen que acaba convirtiéndose en fantasmagórica: ahora el campo epistemológico de la «expresión cinematográfica» no resulta mutilado —como en otras ocasiones-, pero su articulación se encuentra en el límite de "lo real» porque se articula con una música, podríamos decirlo así, fantasmagórica. La banda de sonido crea una tensión en relación a la imagen y, por tanto, además del estatus ontológico, las imágenes están impregnadas de una dominancia del estatus narrativo-funcional en la secuencia; hay una tensión narrativa que aumenta cuanto más avanza la secuencia.

Está claro que las panorámicas del Valle de los Caídos — donde la cámara se va acercando progresivamenteayudan a articular esta sensación fantasmagórica de la muestra; sin embargo, también es cierto que este efecto se consigue con la presencia de esta determinada música. Ésta tiene la suficiente presencia para otorgar un valor ontológico y funcional a la imagen, pero no suficiente para quitarle la «aura» fantasmal.

Como curiosidad, se debe señalar la similitud de la composición de la imagen frente a la tumba del dictador Francisco Franco, con el plano que, mucho más luminoso y más de treinta años después, Portabella realizará frente a la tumba de Johann Sebastian Bach en el filme Die Stille vor Bach (2007).

\section{Conclusiones}

La evaluación del trabajo de Pere Portabella ha permitido identificar con qué mecanismos el director cuestiona la MRI. Los binomios música-imagen que hemos identificado en la obra analizada son uno de los elementos que permiten al director construir una propuesta cinematográfica que cuestione el MRI y tantee nuevas formas de expresión artística, aquellas propias del cine de la modernidad.

Este gesto moderno de articular la música en el cine de Pere Portabella lo podemos resumir en los siguientes puntos:

1) Se suele articula una música cuya estética es ya en sí misma contemporánea —música dodecafónica, concreta, experimental o electrónica-. Aunque ya hemos citado a Michel Chion para explicar la idea de que la evaluación de la música en la modernidad cinematográfica es más una actitud —cómo se articula - que una esencia —qué se articula-, el uso de una música contemporánea es un elemento transcendente que condiciona la construcción de los filmes de Portabella. El abanico estético de la música cinematográfica presente en sus filmes es amplio: desde la música culta de diversos estilos y épocas, a la música pop o a la música electrónica de los primeros años setenta, yendo, así, como ya hemos dicho, a contracorriente del denominado "sinfonismo clásico», propio de la propuesta de la MRI.

2) Portabella articula, de forma repetida, la música con relación a la imagen de tal manera que la «expresión 
cinematográfica» articulada es una reflexión sobre la propia naturaleza de la música y, por extensión, del propio cine -inquietud que el director comparte con muchos de los artistas que le son contemporáneos-. La reflexión sobre el propio lenguaje está en sintonía con el hecho que el "giro lingüístico» sea una de las características comunes de muchas de las artes del siglo XX (Bozal 2004, 20): en lo fílmico «el metacine es el ejercicio cinematográfico que permite al cineasta reflexionar sobre su medio de expresión a través de su práctica» (Canet 2014, 18)—. En este sentido, el debate sobre los límites epistemológicos música-sonido es presente a menudo en su propuesta cinematográfica.

3) Se pone en cuestión la correspondencia causaefecto de la dramaturgia institucional a través de la música y así, en algunos momentos, se prescinde de una de las características fundamentales de la dramaturgia cinematográfica. La transgresión de la unidad del relato aristotélico y su relación de causalidad es un aspecto sobre el que Portabella actúa de manera consciente y así lo manifiesta públicamente en numerosas ocasiones (Cubillo 2007). Si en muchas cinematografías la música refuerza el vínculo causal y narrativo del filme, esto no sucede en la obra de Portabella.

Y 4) La articulación de la música en sus filmes permite al cineasta subvertir el espacio-tiempo diegético institucional que, tal como hemos citado, Bordwell et al. describen como un sistema que construye la dramaturgia, articula el espacio cinematográfico y también el tiempo donde se desarrolla la acción representada. Si hemos dicho que la música le permite a Portabella articular una propuesta no narrativa, el uso de la música en sus filmes le permite la deconstrucción del espacio-tiempo cinematográfico institucional.

Esta subversión estética llega, en algunos fragmentos de Umbracle (1972), a su punto álgido, a su cenit creativo y artístico. La destrucción del espaciotiempo diegético articulado por el MRI se ensaya en muchas de las secuencias producidas en el periodo creativo 1967-1976, pero se concreta, en su expresión más sofisticada, en este filme: los loops icónicos y musicales del fragmento rompen el espacio, el tiempo y la dramaturgia de la diégesis cinematográfica clásica cuando la imagen y la música entran en un bucle y se arrastra la "expresión cinematográfica» a territorios artísticos y expresivos desconocidos hasta el momento. Esta subversión, en definitiva, corrobora la hipótesis de que la particular manera de construir la relación música-imagen en los filmes del director es una de las cuestiones que sitúa al cine de Portabella en una manera de representación propia del cine de la modernidad o de la Manera de Representación Moderna (MRM).

\section{Notas}

${ }^{1}$ Las traducciones al castellano presentes en el artículo, de una fuente original en catalán, han sido realizadas por el propio autor.

2 Formulamos y utilizamos el concepto «expresión cinematográfica» considerando que expresa correctamente la dualidad cinematográfica que contiene imagen y sonido y/o música. Creemos que expresión cinematográfica es un término que define la dualidad de lo fílmico y lo hace de una forma más diáfana que otros conceptos que expresan ideas parecidas, tales como «texto cinematográfico» o «imagen cinematográfica», a menudo citados en la bibliografía.

\section{Bibliografía}

Adorno, Theodor W. (2007). Composiciones para el cine. El fiel correpetidor. Madrid: Akal.

Balázs, Béla (1978). El film: génesis y esencia de un arte nuevo. Barcelona: Gustavo Gili.

Bozal, Valerio (ed.) (2004). Historia de las ideas estéticas y de las teorías artísticas contemporáneas (3a. ed., Vol. 2 [2 Vols.]). Madrid: Antonio Machado Libros.

Benjamin, Walter (2012). La obra de arte en la época de su reproducción mecánica. Madrid: Casimiro libros.

Bordwell, David, Staiger, Janet, Thompson, Kristin (1997). El cine clásico de Hollywood. Estilo cinematográfico y modo de producción hasta 1960. Barcelona: Paidós.

Burch, Noël (2008). El tragaluz del infinito (Contribución a la genealogía del lenguaje cinematográfico) (6a ed.). Madrid: Cátedra.

Canet, Fernando (2014). El metacine como práctica cinematográfica: una propuesta de clasificación. L'Atalante. Revista de Estudios Cinematográficos, 18, 17-26.

Chion, Michel (1993). La audiovisión (Introducción a un análisis conjunto de la imagen y el sonido). Barcelona: Paidós.

- (1997). La música en el cine. Barcelona: Paidós.

Cubillo, Igor (1 de diciembre de 2007). Mi narrativa rompe con los cánones tradicionales del cine. El País.

Duran, Jaume (2013). El tragaluz de lo finito. En Antoni Mercader y Rafael Suárez (eds.), Puntos de encuentro en la iconosfera: interacciones en el audiovisual (pp. 59-72). Barcelona: Publicacions i Edicions de la Universitat de Barcelona.

Fanés, Fèlix (2008). Pere Portabella: avantguarda, cinema, política. Barcelona: Filmoteca de Catalunya y Editorial Pòrtic.

- (2010). Portabella, Brossa, Santos; un Triangle Irregular. Hispanic review, 4, 469-490.

Font, Domènec (2002). Paisajes de la modernidad (Cine europeo, 1960-1980). Barcelona: Paidós.

- (2012). Cuerpo a cuerpo: radiografías del cine contemporáneo. Barcelona: Galaxia Gutenberg.

Fraile, Teresa (2005). Músicas posibles: tendencias teóricas de la relación música-imagen. En M. Olarte (ed.), La música en los medios audiovisuales (pp. 295-314). Salamanca: Plaza Universitaria Ediciones.

- (2008). La creación musical en el cine español contemporáneo. Tesis doctoral. Salamanca: Universidad de Salamanca.

- (2016). Música de cine en España. Crecimiento y consolidación de una disciplina. La Albolafia: Revista de Humanidades y Cultura, 9, 11-30.

Infante del Rosal, Fernando, Lombardo, Manuel (1997). Teorías de la música de cine. En Carlos Colón, Fernando Infante del Rosal, Manuel Lombardo, Historia y teoría de la Música en el Cine (Presencias efectivas) (pp. 205-263). Sevilla: Alfar.

Quintana, Àngel (1996). El Projecte didàctic de Roberto Rossellini. Tesis doctoral. Barcelona: Universitat Autònoma de Barcelona.

Torelló, Josep (2015). La música en las Maneras de Representación cinematográfica. Barcelona: Laboratori de Mitjans Interactius. (Colección Transmedia XXI). 